\title{
Turismo e Unidades de Conservação: análise teórico-conceitual e empírica do uso indireto em parques nacionais brasileiros
}

\author{
Raul Ivan Raiol de Campos \\ Paulo Moreira Pinto ${ }^{b}$ \\ Silvia Helena Ribeiro Cruz ${ }^{\circ}$ \\ Fabrício Lemos de Siqueira Mendes ${ }^{d}$
}

\section{Resumo}

O Sistema Nacional de Unidades de Conservação define uso indireto como aquele que não envolve consumo, coleta, dano ou destruição dos recursos naturais. Neste contexto, a pesquisa problematiza, a partir da aplicabilidade teórica e empírica, se há realmente o uso indireto dos recursos naturais pela atividade turística e pelos moradores locais nos Parques Nacionais dos Lençóis Maranhenses, Jericoacoara e Chapada das Mesas. Nesse conjunto, a centralidade firma-se em analisar o conceito de uso indireto e sua aplicabilidade nos loci citados. Para tanto, utiliza teóricos considerados clássicos e que debatem sobre os recursos de uso comum, cotejando-os com autores contemporâneos. A metodologia consiste em pesquisa bibliográfica e documental, pesquisa de campo, observação direta e abordagem qualitativa. Assim, tomando-se por base os pressupostos teóricos e o empirismo, os resultados demonstram que o que se pratica nessas Unidades de Conservação é o uso direto dos recursos de uso comum tanto pela atividade turística quanto pelos moradores locais.

Palavras-chave: Turismo; Unidades de proteção integral; Uso indireto; Unidades de conservação; Parques nacionais.

\section{Abstract \\ Tourism and Conservation Units: theoretical-conceptual and empirical analysis of the category indirect use in Brazilian national parks}

The National System of Conservation Units defines indirect use as that which does not involve consumption, collection, damage, or destruction of natural resources. In this context, this research questions, from a theoretical and empirical applicability, the existence of an indirect use of natural resources by tourist activity and by residents in the National Parks of Lençóis Maranhenses, Jericoacoara, and Chapada das Mesas. In this set, its centrality is based upon analyzing the concept of indirect use and its applicability in

a. Doutorado em Desenvolvimento Sustentável do Trópico Úmido pelo Núcleo de Altos Estudos Amazônicos/Universidade Federal do Pará. Docente de Turismo na Universidade Federal do Pará. Belém, Pará, Brasil. E-mail: raulcampos@ufpa.br

b. Doutorado em Desenvolvimento Sustentável do Trópico Úmido pelo Núcleo de Altos Estudos Amazônicos/Universidade Federal do Pará. Docente de Turismo na Universidade Federal do Pará. Belém, Pará, Brasil. E-mail: pmpinto@ufpa.br

c. Doutorado em Desenvolvimento Sustentável do Trópico Úmido pelo Núcleo de Altos Estudos Amazônicos/Universidade Federal do Pará. Docente de Turismo na Universidade Federal do Pará. Belém, Pará, Brasil. E-mail: silhcruz@gmail.com

d. Doutorado em Desenvolvimento Sustentável do Trópico Úmido pelo Núcleo de Altos Estudos Amazônicos/Universidade Federal do Pará. Docente de Turismo na Universidade Federal do Pará. Belém, Pará, Brasil. E-mail: fabriciolsm@ufpa.br 
these loci. For that, it uses classic authors who discuss common use resources, comparing them with contemporary researchers. The methodology consists of bibliographic and documentary research, field research, direct observation, and qualitative approach. Thus, based on theoretical assumptions and empiricism, the results demonstrate that what is practiced in these Conservation Units is the direct use of common use resources both by tourism and residents.

Keywords: Tourism; Integral protection units; Indirect use; Protected areas; National parks.

\section{Resumen}

Turismo y Unidades de Conservación: análisis teórico-conceptual y empírico del uso indirecto en parques nacionales brasileños

El Sistema Nacional de Unidades de Conservación define uso indirecto como aquel que no involucra consumo, recolección, daño o destrucción de los recursos naturales. En este contexto, esta investigación problematiza, desde la aplicabilidad teórica y empírica, si hay realmente el uso indirecto de los recursos naturales por la actividad turística y por los residentes en los Parques Nacionales de Lençóis Maranhenses, Jericoacoara y Chapada das Mesas. En ese conjunto, se centra en analizar el concepto de uso indirecto y su aplicabilidad en los loci citados. Para ello, se utilizan referenciales teóricos considerados clásicos y que debaten los recursos de uso común, cotejándolos con autores contemporáneos. Esta es una investigación bibliográfica y documental, de enfoque cualitativo, basada en la investigación de campo y observación indirecta. Así, tomando como base los supuestos teóricos y el empirismo, los resultados demuestran que lo que se practica en esas Unidades de Conservación es el uso directo de los recursos de uso común tanto por la actividad turística como por los locales.

Palabras clave: Turismo; Unidades de protección integral; Uso indirecto; Unidades de conservación; Parques nacionales.

\section{INTRODUÇÃO}

As origens históricas das áreas protegidas datam de 700 a.C na Assíria com o registro das reservas reais de caça. Na Inglaterra, os normandos estabeleceram no século XI a "Nova Floresta", que foi a primeira floresta real de caça (Colchester, 2003). Porém, a concepção moderna de áreas protegidas surgiu a partir da segunda metade do século XIX, tendo como seus principais defensores George Catlin e John Muir (Nash, 1967). Nesta perspectiva, foram criados os primeiros Parques Nacionais (PARNA), com destaque para Yellowstone, nos Estados Unidos da América, baseado na concepção de wilderness, de parques sem a presença de moradores. Tal concepção preservacionista estabeleceu uma dicotomia entre o ser humano e a natureza, considerando a presença do homo sapiens incompatível com o ambiente natural. Portanto, permitindo somente o uso indireto dos PARNA.

Estudos contemporâneos sobre o uso sustentável em Unidades de Conservação (UC) abordam o chamado uso público relacionado ao benefício que este pode gerar 
para o turismo (Simonetti \& Nascimento, 2012), o mapeamento do uso público dos PARNA (Semeia, 2015), o papel dos gestores, visitantes e prestadores de serviços (Vallejo, 2013). Outros estudos, como os de Santana, Fontes Filho e Rocha (2015), versam sobre os recursos de uso comum e a gestão local, sob a perspectiva do pensamento de Elinor Ostrom, no Parque Estadual da ilha do Cardoso.

Todavia, não se conseguiu identificar, nos loci escolhidos para a investigação, estudos que problematizem a ocorrência do uso indireto nestas Unidades de Proteção Integral (UPI). Esta pesquisa parte da hipótese da inexistência do uso indireto nos PARNA dos Lençóis Maranhenses, Jericoacoara e Chapada das Mesas. A afirmação proposta permitiu realizar a análise teórico-conceitual e empírica do uso indireto nos referidos PARNA. Ressalte-se que o Sistema Nacional de Unidades de Conservação (SNUC) defini uso indireto como "aquele que não envolve consumo, coleta, dano ou destruição dos recursos naturais" (Brasil, 2008, p. 16). Nesse conjunto, o estudo objetiva analisar o entendimento normativo do uso indireto e sua aplicabilidade nos PARNA mencionados. A escolha dos PARNA deve-se as práticas de campo do curso de graduação em turismo da Faculdade de Turismo (FACTUR), da Universidade Federal do Pará (UFPA), envolvendo temas relacionados às disciplinas: estrutura e manejo de unidades de conservação, análise de impactos socioambientais e planejamento e gestão do ecoturismo.

\section{PROCEDIMENTOS METODOLÓGICOS}

Incialmente, foram realizadas pesquisas bibliográfica e documental em livros, teses, artigos (Oliveira, 1998; Severino, 2007), planos de manejos e outros documentos pertinentes a este estudo, que possibilitaram problematizar as categorias de UC de uso indireto. Tais pesquisas, serviram de suporte para abordar os aspectos históricos, sociais e ambientais, principalmente os relacionados às atividades de subsistência e de turismo, e suas relações com uso indireto ou não nos três parques nacionais escolhidos como os loci da pesquisa.

Complementarmente foi realizada pesquisa de campo com objetivo de verificar se as atividades de subsistência e turismo eram consideradas de uso indireto ou não, a fim de confirmar ou refutar a hipótese deste estudo, confrontando-as com as pesquisas bibliográfica e documental. Para tanto, foi realizada a observação direta, conforme posto por Marconi e Lakatos (2003), apurando-se os sentidos para apreensão dos fatos e fenômenos que se quer estudar.

Esta pesquisa foi pautada pela abordagem qualitativa (Oliveira, 2007; Moreira \& Caleffe, 2008), pois o foco central não foi a mensuração quantitativa das informações, mas a recorrência ou pattern nas repostas, no sentido de contribuir com os fatos observados em campo. Por isso, utilizou-se entrevistas informais seguindo as recomendações mencionadas por Bernard (1995) e Schütler (2003). As entrevistas foram utilizadas para subsidiar a observação direta (Camargo, 1978). Foram realizadas 13 entrevistas no PARNA da Chapada das Mesas, 20 entrevistas no PARNA de Jericoacoara e 24 no PARNA dos Lençóis Maranhense. As entrevistas com representantes do poder público (secretários municipais de turismo) e com os gestores dos parques foram previamente agendas, porém com a população local foram aleatórias. 
As aproximações com as áreas de estudo adotaram o prescrito por Babbie (1999) sobre corrigir erros e superar as pré-noções, e foram realizadas em novembro de 2015 e dezembro de 2016, no PARNA de Jericoacoara; em abril de 2016 no PARNA da Chapada das Mesas; e em meses alternados nos anos de dezembro de 2012, abril de 2015 e novembro de 2017, no PARNA dos Lençóis Maranhenses. Esses períodos estão conexos com as atividades de campo das disciplinas do curso de graduação em turismo da FACTUR/UFPA relacionadas com impactos socioambientais, estrutura e manejo de unidades de conservação e planejamento do ecoturismo.

\section{USO INDIRETO, USO DIRETO E RECURSOS DE USO COMUM}

O surgimento do termo uso indireto teve origem com a criação das áreas protegidas no mundo. O Parque Nacional de Yellowstone foi uma das primeiras áreas protegidas criada tendo como base a abordagem não-utilitária ${ }^{1}$ (uso indireto) do wilderness, que teve como fundamento a ideologia de apreciação (recreação) (Nash, 1967) e a separação do ser humano da natureza criada pela visão preservacionista. Segundo Diegues (2001, p.28) a perspectiva preservacionista é a "reverência à natureza no sentido da apreciação estética e espiritual da vida selvagem (wilderness). Ela pretende proteger a natureza contra o desenvolvimento moderno, industrial e urbano". Portanto, a concepção preservacionista defende uso indireto ou não-utilitário dos PARNA como uma consequência da relação dicotômica da suposta incompatibilidade do ser humano com a natureza.

A abordagem não-utilitária enfatiza os valores estéticos, emocionais, espirituais e éticos da natureza (Loreau, 2014). Loreau (2014) considera que um organismo, espécimen, ecossistema ou até mesmo a biosfera tem um valor intrínseco, independente do uso pelos seres humanos. Para o autor, o valor intrínseco representa o valor da entidade em si mesma. A abordagem não-utilitária é base para a ética ambiental que busca novos princípios éticos para governar as atitudes dos seres humanos para com os outros seres e a natureza (Loreau, 2014).

Contrariamente, a abordagem utilitária (uso direto) enfatiza que as espécies e ecossistemas são recursos para os seres humanos, que precisam ser gerenciados sustentavelmente para se evitar escassez de recursos com dano para economia e a sociedade (Loreau, 2014). As tensões entre essas abordagens são antigas. Os que defendem a abordagem não-utilitária criticam os utilitaristas por serem antropocêntricos e por fornecerem argumentos inconsistentes para a conservação. Os utilitaristas criticam os não utilitaristas pelo seu dogmatismo e por não serem pragmáticos (Loreau, 2014). Ambas abordagens estão presentes nas Unidades de Conservação brasileiras.

A base legal para a proteção da natureza no Brasil iniciou a partir da Constituição de 1934, na qual deveriam concorrer para sua proteção a União e os estados (Medeiros, 2006). Também, em 1934 foi criado o primeiro Código Florestal que instituiu na categoria de Florestas Remanescentes a criação dos PARNA que constituíam monumentos públicos e naturais (Brasil, 1934). 0

1. A categoria não-utilitária é usada na literatura internacional para se referir ao uso indireto. 
referido código proibiu a exploração dos recursos naturais dos PARNA. Nesse aspecto, o Código Florestal de 1965 (Brasil, 1965) instituiu a categoria proteção integral dos recursos naturais, bem como impedia o uso direto desses recursos.

Em seu relatório sobre o curso em Forestry Leadership a convite da United States Agency for International Development (USAID), Alceo Magnanini, em 1965, menciona a necessidade da utilização direta da floresta (atividades florestais) e a utilização indireta (atividades conservacionistas) (Barreto Filho, 2010). Magnanini foi o responsável pelos embates para a inclusão do artigo acima mencionado que trata da proteção integral e uso indireto (implícito) no Código Florestal de 1965 (Barreto Filho, 2010).

Contudo, o termo "uso indireto" foi mencionado pela primeira vez no documento Plano do Sistema de Unidades de Conservação do Brasil, publicado em 1979. O documento faz referência ao uso indireto de preservação da natureza, "[...] onde o melhor uso é não usar diretamente esses recursos, mas, sim obter um benefício indireto dos mesmos" (Brasil, 1979, p. 6). No documento, o uso indireto dos recursos naturais significa sem consumo.

Entretanto, o conceito de uso indireto foi institucionalizado em lei com a criação do Sistema Nacional de Unidades de Conservação (SNUC). Após longa tramitação no Congresso Nacional, o SNUC foi aprovado nos anos 2000 (Medeiros, 2006). Teoricamente, o uso indireto em PARNA (UC de proteção integral) pode ocorrer mediante atividades de recreação, educação, interpretação ambiental e turismo, de acordo com as normas e restrições estabelecidas no plano de manejo.

A International Union for Conservation of Nature (IUCN) apresenta uma outra perspectiva sobre o uso indireto. A IUCN (1998) considera os valores de uso indireto aqueles relacionados às funções ecológicas das áreas protegidas. Por outro lado, ela considera os valores de uso direto das áreas protegidas relacionados às atividades tais como recreação, turismo, educação, pesquisa, patrimônio genético e coleta de recursos naturais. $\mathrm{O}$ entendimento sobre uso indireto da IUCN diverge do entendimento e do conceito sobre esta categoria de análise presente no SNUC, pois o que o SNUC considera como uso indireto, a IUCN considera como uso direto das áreas protegidas. Portanto, este estudo é consoante ao entendimento da IUCN sobre o uso direto, porque o turismo e as atividades de subsistência são atividades econômicas e sociais que têm impacto sobre os recursos naturais e culturais dos PARNA.

0 uso direto dos recursos ocorre sobre os chamados recursos de uso comum, que podem ser analisados pela Teoria dos Recursos de Uso Comum. Os recursos de uso comum incluem os sistemas naturais e os feitos pelo ser humano (Ostrom, 2002). Recursos de uso comum são dunas, restingas, praias, rios, animais, plantas, cachoeiras, florestas, cerrado etc. A utilização dos recursos de uso comum está no centro dos dilemas sociais que resultam do conflito entre os interesses individuais e coletivos.

Um dos primeiros autores no mundo a tratar do uso dos recursos comuns foi Hardin (1968) ao afirmar que os problemas dos dilemas sociais, ou dilemas da ação coletiva, são a contradição entre a racionalidade individual e racionalidade coletiva. Para ele (1968) um indivíduo agindo de forma racional usa os recursos comuns de forma ilimitada, maximiza os benefícios, mas distribui os custos para os outros membros do grupo deixando-os em situação ruim. Porém, para evitar a tragédia, ele propôs que os recursos deveriam ser privatizados ou ter controle 
do Estado, porque os usuários locais não conseguirão resolver o problema por si próprios. Portanto, a criação de áreas protegidas seria uma das formas do controle do Estado sobre o uso dos recursos comuns.

Para resolver os dilemas sociais, Ostrom (1998) considera a relação entre reciprocidade, reputação e confiança, que afetam os níveis de cooperação e benefícios. Essa relação tem importância para a argumentação de Ostrom (1999; 2002) sobre a gestão dos recursos auto-organizados, em que os usuários de uma comunidade se preparam com objetivo de criar regras que estabelecem direitos e deveres para um bem público usado por todos os envolvidos. Ostrom (1999; 2002) cita como exemplo de gestão de recursos auto-organizados uma pesquisa feita com agricultores no Nepal, que tem regras e sistemas de manejo não gerenciados pelo governo. Isto vai de encontro à teoria de Hardin e demonstra que o Estado não consegue gerenciar os recursos naturais sozinhos.

Os recursos de uso comum possuem duas características que são: a exclusão e subtração. A exclusão implica na "dificuldade de excluir indivíduos de se beneficiarem de um bem" (Ostrom, Gardner \& Walker, 1994, p. 6). Na exclusão, o controle de acesso dos potenciais usuários pode ser oneroso ou quase impossível devido à natureza física do recurso (Fenny et al., 1990).

A subtração implica que cada usuário é capaz de enfraquecer o bem-estar de outros usuários. Implica no nível exploração por um usuário que afeta negativamente/contrariamente à exploração do recurso por outros usuários (Feeny et al., 1990). Refere-se ao grau de subtração de um usuário do que fica disponível para os outros usuários (Ostrom et al., 1994). Por exemplo, se houver superexploração de um recurso por um indivíduo, ele estará indisponível para outros usuários.

A partir das características e dos tipos de bens, os recursos de uso comum, segundo Fenny et al. (1990) podem ser mantidos em quatro regimes de propriedade: acesso livre, propriedade privada, propriedade comunal e propriedade estatal. No regime de propriedade estatal, os recursos de uso comum são controlados pelo Estado, que decide o acesso e o grau de exploração dos recursos. Nessa categoria de propriedade o Estado tem poder coercitivo, o público em geral tem acesso e direitos de uso iguais, por exemplo parques públicos (Fenny et al., 1990).

O êxito na regulação de usos e de usuários não está associado com nenhum tipo específico de regime de propriedade, visto que o êxito e o fracasso podem acontecer nos regimes de propriedade privada, comunal e estatal. Entretanto, nos países menos desenvolvidos, no qual o cumprimento das leis é problemático, no regime de propriedade estatal, o manejo dos recursos dificilmente está associado ao êxito (Fenny et al., 1990). Este é o caso do Brasil, no qual a gestão e a fiscalização das UC são deficientes, devido à ausência de planos de manejo ou de sua efetivação, ou seja, são criados, mas não concretizados; equipe reduzida de funcionários para fiscalização e os problemas fundiários. As características dos recursos de uso comum, os tipos de bens e os regimes de propriedades são importantes para entender o uso indireto ou direto nos PARNA objeto deste estudo. Os PARNA são propriedade do Estado, são posse e domínio público, mas alguns deles ainda tem propriedades privadas e posseiros. 


\section{OS PARQUES NACIONAIS: USO INDIRETO OU USO DIRETO?}

Aborda-se os aspectos históricos de criação dos PARNA, a situação fundiária das famílias, as atividades de subsistência das comunidades existentes, e as atividades de turismo, buscando evidenciar se essas atividades constituem uso direto ou indireto dos PARNA, conforme abordados no item anterior.

\section{O PARNA dos Lençóis Maranhenses}

O PARNA dos Lençóis Maranhenses (PNLM) foi proposto no documento intitulado Plano do Sistema de Unidades de Conservação do Brasil (Brasil, 1979). Porém, sua criação ocorreu em 1981 pelo Decreto Federal n. 86.060, abrangendo uma área de 155.000 hectares e um perímetro de $270 \mathrm{~km}$, abrangendo os municípios de Primeira da Cruz (6,89\%), Santo Amaro (42,15\%) e Barreirinhas $(44,86 \%)$, seu acesso ocorre pela rodovia MA-402 até Barreirinhas onde se localizada a principal entrada para o PNLM (Brasil, 2003).

O PNLM (Figura 1) tem grande parte de sua extensão coberta por dunas e lagoas que abrange os três municípios (Brasil, 2003). Possui cerca de 90.000 ha de dunas livres e lagoas interdunares de água doce (Terra, 2017). A situação fundiária do PNLM é: 29\% de propriedades com registros e 215 famílias consideradas posseiras $^{2}$. Desse total, foram consideradas populações tradicionais as comunidades de Baixada Grande, Queimada dos Britos e Travosa (Brasil, 2003).

Figura 1 - Mapa de Localização do PNLM

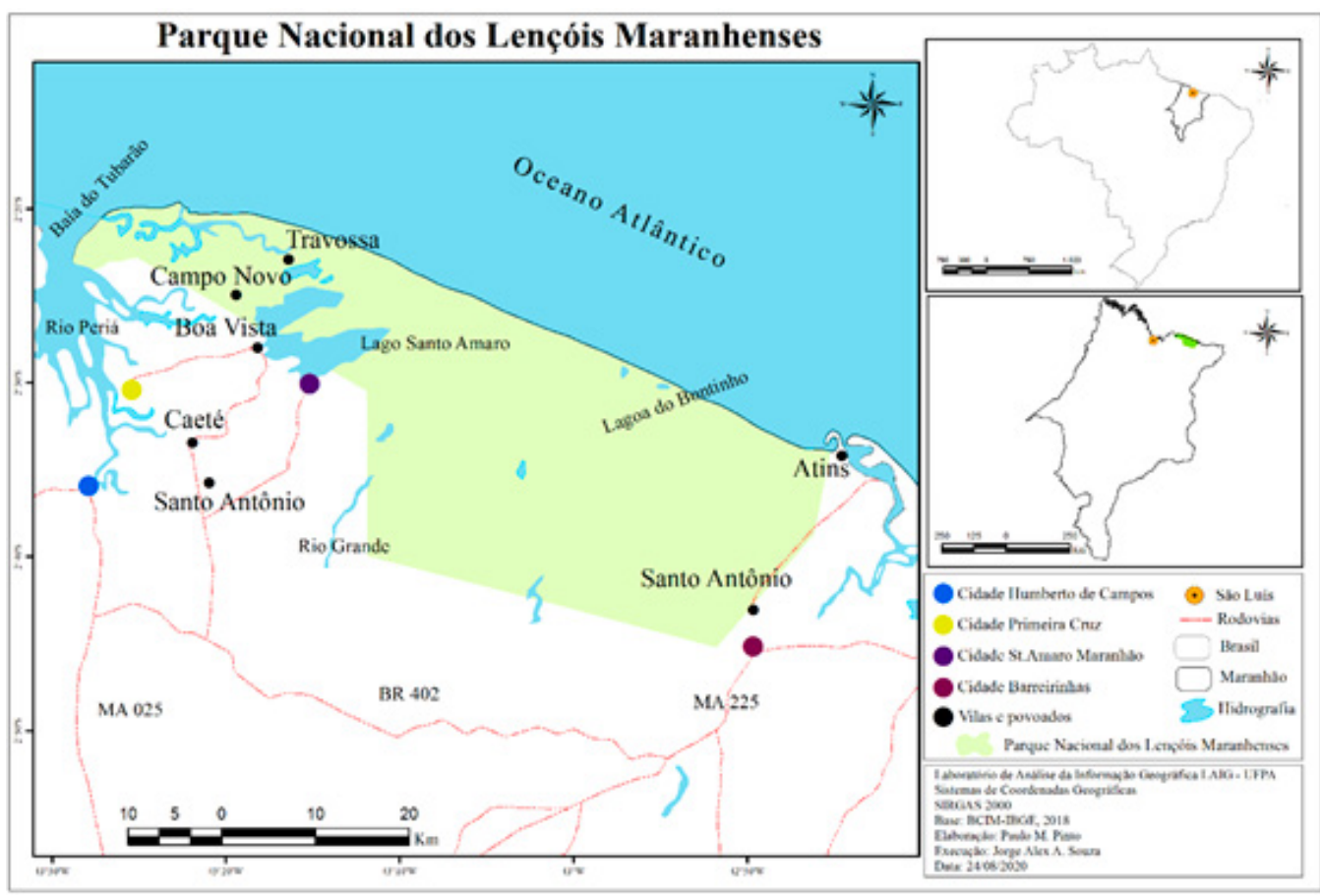

Fonte: Pinto e Souza (2020).

2. Os PARNA são posse e domínio públicos, sendo suas áreas particulares desapropriadas. 
Porém, estudo realizado por D’Antona (2002) constatou que, a partir de dados de 1997, a existência de um universo de 525 localidades na região do PNLM, sendo que 53 localidades no interior dele. Isto perfaz uma população de 3.646 pessoas, que corresponde a 7,39\% do universo de localidades. De acordo com Terra (2017), existem 17 comunidades no PNLM.

A combinação das atividades de lavoura, pesca, extrativismo, pecuária e olaria é traço geral das comunidades dos Lençóis Maranhenses (D’Antona, 2000). Porém, as localidades possuem atividades específicas, como as que moram junto ao rio Preguiças. Por exemplo, a localidade de Laranjeiras tem como principal atividade a fabricação de tijolos; a localidade de Tapuio a lavoura. Mas no inverno elas migram para a praia para pescar, pois o inverno não é uma estação boa para suas atividades principais (D’Antona, 2000).

Apesar de o interior do PNLM ser um deserto, existem localidades de comunidades residentes, com por exemplo Baixada Grande e Queimadas dos Britos com cerca de 100 famílias. Essas localidades são uma espécie de "ilha" em meio ao deserto. Na Baixada Grande as atividades de subsistência consistem em agricultura, extrativismo, pecuária e pesca, com destaque para o arroz, feijão, castanha e gado bovino. A pesca acontece principalmente no inverno. 0 gestor do PNLM, em entrevista, mencionou que atividades de cultivo (mandioca, feijão) e de criação de animais (porcos, cabras, carneiros, bois e cavalos) praticadas pelos moradores causam impactos no parque.

O turismo tornou-se uma das principais atividades do PNLM, cuja visitação começou em 2001(Brasil, 2003). A atividade no PNLM tem como um dos objetivos "contribuir para o desenvolvimento local e regional atuando como pólo difusor das atividades de ecoturismo" (Brasil, 2003, p. 138). 0 município de Barreirinhas é o principal portal de acesso ao PNLM, por isso teve sua dinâmica econômica e social transformada com o turismo. Segundo Silva (2008), outras atividades importantes deram lugar ao turismo, causando o deslocamento da população para o centro urbano em busca de novas fontes de renda. Mas, de acordo com a secretaria de turismo de Barreirinhas, 90\% dos turistas vêm para conhecer o parque, poucos fazem turismo na cidade.

O Plano de Manejo do PNLM (Brasil, 2003) estabeleceu um limite de 100 visitantes diários na alta estação para os períodos matutino e vespertino e de 60 visitantes diários na baixa estação em ambos os períodos. Estudo realizado por Silva (2008) mostrou que a visitação nas Lagoas Azul e do Peixe, teve uma visitação de 52.819 turistas, com uma média de 144,7 turistas por dia. Portanto, acima do limite estabelecido no Plano de Manejo.

Os dados do Instituto Chico Mendes de Conservação da Biodiversidade (ICMBio) mostram que houve um aumento de 40.000 para 107.000 visitantes, do ano de 2015 para 2018. Portanto, nos últimos 4 anos houve um aumento de $167,5 \%$ no número de visitantes. Este aumento de mais de $160 \%$ tem implicações na preservação do PNLM. Para Silva (2008), o turismo é uma atividade massificada que compromete a sustentabilidade da região do PNLM, causando mais danos que a população residente. 0 autor ressalta que enquanto o turismo destrói o PNLM, a comunidade local que pratica atividade de subsistência não pode desenvolver suas atividades por imposição legal. 
O turismo alterou a dinâmica social, econômica e ambiental das localidades, pois os pescadores usavam somente para sua atividade sazonal (Silva, 2008). Por exemplo, nos Pequenos Lençóis, a localidade de Caburé que é o último ponto de parada onde o turista/visitante permanece mais tempo para almoço, banho de mar ou rio, pois está na foz do rio Preguiças, o turismo alterou a dinâmica social, econômica e ambiental da localidade, pois houve a instalação de infraestrutura de pousadas e restaurantes, além das embarcações de fazem o deslocamento dos turistas.

De acordo com D’Antona (2000), o Caburé era usado pelos pescadores somente para sua atividade sazonal. Porém, o turismo tornou-se uma atividade permanente, comprometendo a sua preservação. Esta localidade faz parte da APA Foz do rio Preguiças, Pequenos Lençóis, Região Lagunar Adjacente criada em 1991, é também a Zona de Amortecimento (ZA) do PNLM, além de ser uma APP. Por isso, legalmente não deveria haver o uso direto nessa área. Para Silva (2008) Caburé não deveria ter infraestrutura turística, nem visitação massiva devido a fragilidade da restinga. Os moradores das comunidades (Tapuio, Vassouras, Mandacaru e Caburé) reconhecem que o turismo trouxe benefícios, por exemplo, por meio da venda de artesanato e alimentação, mas também mencionaram o excesso de turistas, causam problemas ambientais como o lixo.

\section{O PARNA de Jericoacoara}

Historicamente, Jericoacoara foi uma área habitada pelos índios Tremembé, que viviam da caça e da pesca (Molina, 2007; Machado, 2013). Era uma pequena comunidade de pescadores, um local pacato e calmo (Molina, 2007; Machado, 2013). Segundo Molina (2007, p. 40), o termo Jericoacoara vem das palavras "Yuruco" (buraco) e "Cuara", que significa "o buraco das tartarugas". 0 termo faz sentido por Jericoacoara ser um berçário natural onde as tartarugas marinhas cavam e põem seus ovos (Machado, 2013). De acordo com Molina (2007), era um local de difícil acesso, pois para se chegar até a vila tinha que atravessar as dunas.

A primeira UC estabelecida foi a Área de Proteção Ambiental Jericoacoara (APA Jericoacoara) criada em 1984 pela Secretaria Especial de Meio Ambiente (SEMA), abrangendo uma área de 5,480 ha (Brasil, 1984). 0 objetivo da APA Jericoacoara era proteger e preservar os ecossistemas de mangues, praias, restingas dunas e formações geológicas (Brasil, 1984). Entretanto, a APA não teve o resultado esperado, devido o interesse de invasores e especulação imobiliária (Machado, 2013).

Por isso, com o Decreto Federal de fevereiro de 2002, foi criado o PARNA de Jericoacoara (PNJ), que incluiu parte da APA Jericoacoara, com uma área de 8.416 h (Brasil, 2002). Posteriormente, o referido decreto foi revogado em 2007, pela lei no. 11.486, que alterou os limites do PNJ aumentando-o para 8.850 ha (Brasil, 2007). Esta ampliação extinguiu a APA (Macedo, 2013). 0 PNJ abrange 60,22\% do município de Jijoca de Jericoacoara, 13,81\% do município de Cruz e 25,97\% de Área de Marinha (União), localizado a $300 \mathrm{~km}$ de Fortaleza (capital do Estado), entre os rios Guriú e Acaraú (Brasil, 2011), (Figura 2). 
Figura 2 - Mapa de localização do PNJ

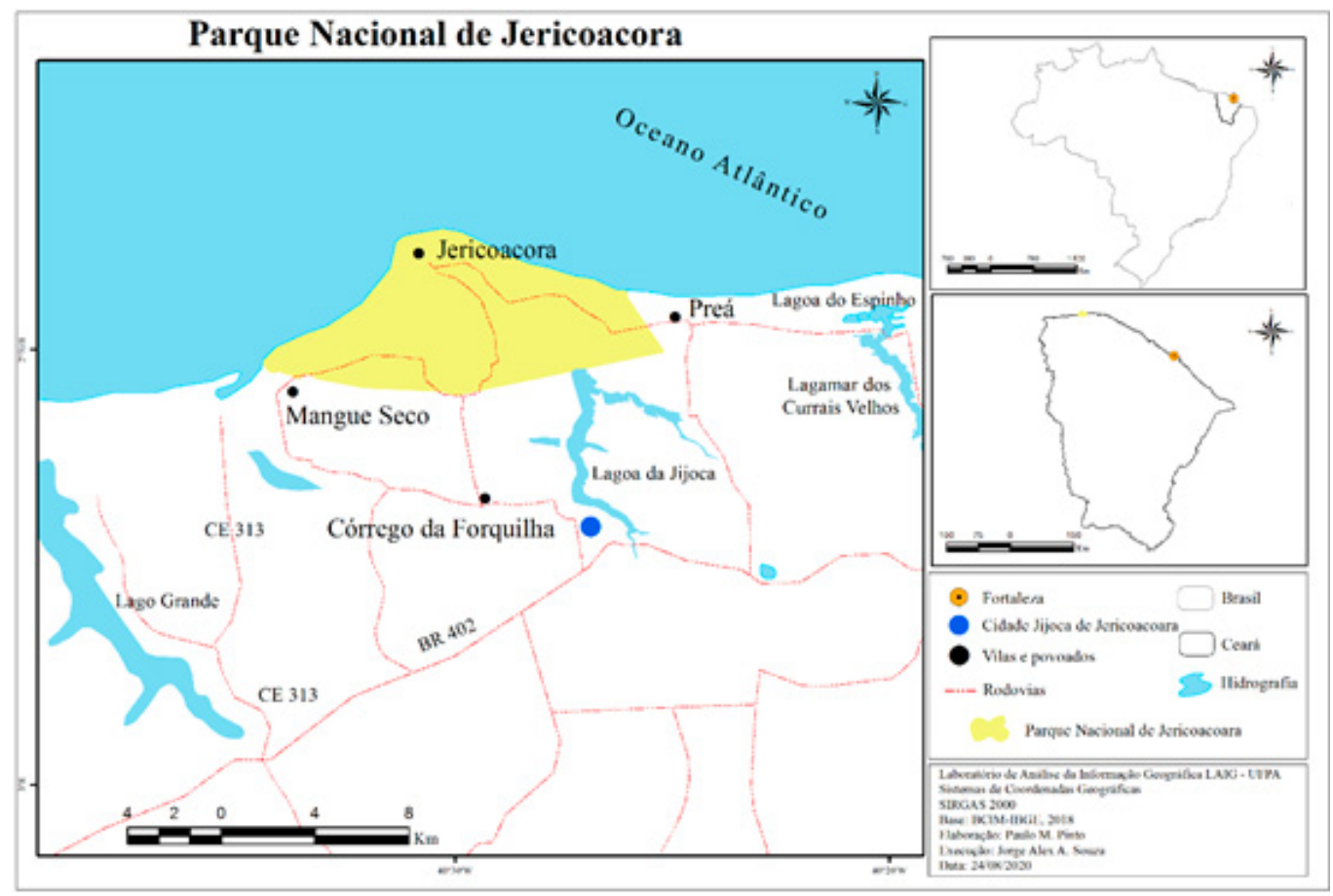

Fonte: Pinto e Souza (2020).

Existem três comunidades que ocupam 40 hectares de extensão do PNJ. São as comunidades de Lagoa Grande, Junco e Mangue Seco, que representam respectivamente $52 \%$, 35\% e $13 \%$ desse total de hectares. A maioria da população residente no PNJ se estabeleceu muito antes da criação da UC. Portanto, devido não terem a titularidade da terra, são caracterizadas como posseiras, mas não invasoras. Essas comunidades totalizam 26 famílias, perfazendo um total de 100 pessoas. Porém, a comunidade de Lagoa Grande tem maior número de residências, cuja ocupação está em torno de 30 a 40 anos, sendo que alguns moradores dessa comunidade possuem declaração de posse (Brasil, 2011).

As atividades socioeconômicas de Jericoacoara podem ser caracterizadas em dois momentos: antes e depois do turismo. Jericoacoara era uma pequena vila constituída de pescadores artesanais, agricultores de subsistência e artesãos que confeccionavam instrumentos de pescas e peças de croché. Devido ao difícil acesso as principais cidades, a economia era restrita a venda no comercio local em mercearias e ao escambo de peixe por outros alimentos (Fonteles, 2005).

Atualmente, a economia de subsistência é baseada na agricultura com plantio de roças, principalmente de mandioca, seguido de milho, feijão, batata e extração da castanha de caju. Criação de cabras, galináceos que fazem parte da subsistência dos moradores do PNJ. O uso dos recursos pesqueiros também é fonte de sobrevivência de famílias que pescam nas praias de Mangue Seco e do Riacho Doce utilizando o arrasto e tarrafa (Brasil, 2011).

Os moradores do PNJ com suas respectivas áreas de uso estão na Zona de Ocupação Temporária. Esta zona permanecerá até que medidas legais sejam adotadas para retirada das populações locais, sendo que está situação prevalece desde o zoneamento do PNJ. A Vila de Jericoacoara está inserida na Zona de Amortecimento (ZA) por ter influência no trânsito de pessoas ao longo do PNJ e por ser um polo atrativo de turismo. Dentre os impactos causados na ZA estão: 
"as queimadas, a implantação de empreendimentos eólicos, o extrativismo do caju, a exploração de areia e o turismo desordenado" (Brasil, 2011, p. 4-59).

A atividade turística iniciada nos anos de 1970, causou transformações na dinâmica social, cultural, ambiental, econômica e no território da vila de Jericoacoara. Com tais transformações sociais e econômicas, os moradores passaram a exercer outras profissões, como: "[...] garçons, guias, vendedores ambulantes, arrumadeiras, serventes de pedreiros, dentre vários outros tipos." (Fonteles, 2005, p. 50). Houve um processo de descaracterização da identidade, que se tornou produto de consumo (Molina, 2007). É perceptível que Jericoacoara tornou-se um lugar sem identidade. Ela tornou-se um lugar cosmopolita. Desse modo, criou-se um não-lugar de acordo com a teoria de Augé, (1994).

Na gestão do território, os outsiders do trade turístico adquiriram as terras que eram dos moradores para construções, em desacordo com a arquitetura local, causando crescimento desordenado da Vila de Jericoacoara (Fonteles, 2005). Observou-se que, na vila os residentes estrangeiros são italianos, franceses, portugueses etc. Os estrangeiros e brasileiros de outros estados são os proprietários dos principais estabelecimentos comerciais (mercados, lojas de souvenires, pousadas, restaurantes etc.).

Os impactos socioambientais observados a partir das entrevistas com o gestor da UC e com os moradores destacam-se: lixo; entulho; contaminação por esgoto no interior do PNJ; trânsito descontrolado de veículos que causam impactos sobre dunas; atropelamento de animais como as tartarugas; excesso de animais domésticos; abandono de gado; excesso de turistas (overtourism) na alta temporada, pois não há estudo de capacidade de carga para os atrativos mais visitados pelos turistas dos quais destacam-se, a praia de Jericoacoara, praia da pedra furada, Lagoa de Princesa, Árvore do Macaco e a Duna Pôr-do-sol.

Para exemplificar o impacto do overtourism cita-se o exemplo da Duna Pôr-doSol, de acordo com o gestor do PNJ, ela possuía mais de 100 metros de altura, porém atualmente possui cerca de 80 metros de altura devido ao número elevado de turistas que vão ao seu topo todos os anos. Meireles, Gorayeb e Pereira Filho (2018) evidenciaram alterações nas dunas provocadas pela atividade turística. Além de detectar a diminuição das dunas próximas ao setor urbano da vila e do Serrote de Jericoacoara. Portanto, o que comprova a diminuição da Duna Pôr-doSol pelo excesso de turistas, conforme relatado pelo gestor do parque.

O impacto causado na Duna Pôr-do-Sol tem relação direta com o aumento do número de visitantes no PNJ. Dados do ICMbio mostram um aumento no número de visitantes no período de 2015 a 2018, respectivamente de 780.000 para 1.091.829. Portanto, houve um aumento de 39,97\% no número de visitantes. Desse modo, o dano causado na duna ocorre pelo excesso visitantes, devido à falta de controle ao acesso à duna e a ausência de estudo de capacidade de carga.

\section{O PARNA da Chapada das Mesas}

A primeira proposta de criação do PARNA da Chapada Mesas (PNCM) ocorreu em 1973, por meio dos levantamentos do projeto RADAMBRASIL, tendo recebido a denominação de Mesas de Carolina. A segunda tentativa consta no documento Planejamento do Sistema Nacional de Unidades de Conservação 
de 1977, no qual aparece com a denominação de "Parque Nacional da Mesas", cujos levantamento dos limites foram realizados pelo projeto RADAMBRASIL (Silva, Araújo, \& Conceição, 2019).

O PNCM foi criado no dia 12 de dezembro de 2005 devido à possibilidade de construção de pequenas hidrelétricas nas cachoeiras de São Romão e Prata no rio Farinha. Por esse motivo, em 2003, a população do município de Carolina e o poder público local elaboraram um dossiê ao Ministério do Meio Ambiente, no qual solicitavam a criação do PARNA (Instituto Brasileiro de Meio Ambiente e dos Recursos Naturais Renováveis, [IBAMA], 2007). O PNCM serve como ecótono para os biomas do Cerrado, Amazônia e Caatinga. Possui uma área de 160.046.00 ha, dividida em duas glebas de 140.000 e 19.000 ha, respectivamente.

O PNCM está localizado no sudoeste do estado do Maranhão (Figura 3), abrangendo os municípios de Carolina, Estreito e Riachão (IBAMA, 2007). 0 acesso é feito pelos municípios de Estreito e Carolina pela BR-230, rodovia pavimentada em bom estado de conservação. Porém, a entrada mais próxima do PNCM ocorre pelo município de Carolina.

Figura 3 - Mapa de localização do PNCM

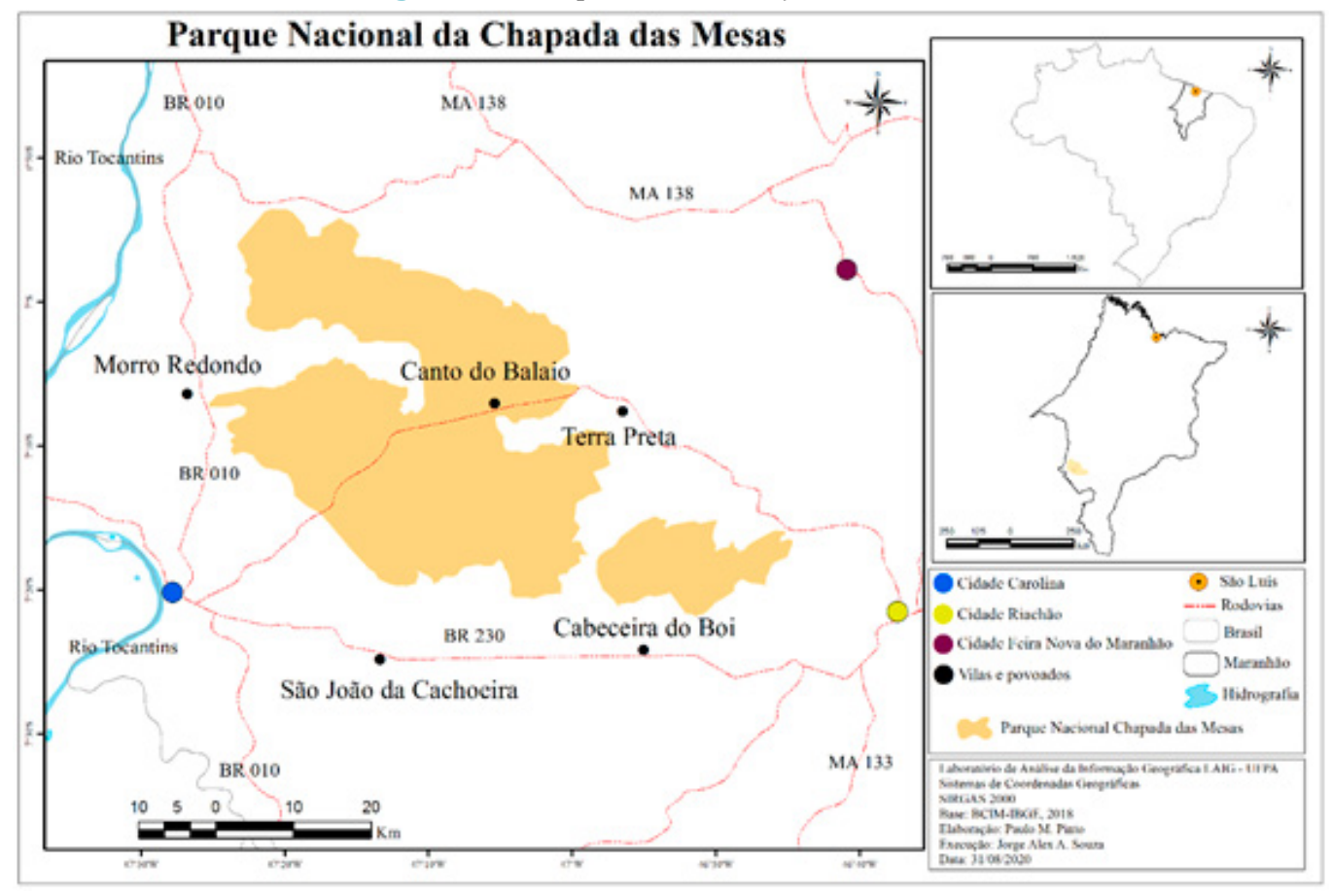

Fonte: Pinto e Souza (2020).

O PNCM possui um relevo plano-ondulado, com altitudes que variam de 250 $\mathrm{m}$ nos vales a $524 \mathrm{~m}$ nas chapadas, com morros compostos de arenito elevados, cujas formas foram esculpidas pela ação do vento e das chuvas. Por ter topo dos morros planos em formato de mesetas foram denominados de Chapada das Mesas (IBAMA, 2007). De acordo com o gestor do PNCM, existem mais de 300 morros (mesetas) de arenito.

No PNCM há o predomínio da vegetação do bioma Cerrado, porém, são encontradas espécies dos biomas da Amazônia e Caatinga (IBAMA, 2007). Dentre os recursos naturais encontrados estão os cursos d'agua, matas e brejos que são compostos em sua maioria por buritizais, palmeiras, jussarais e veredas (Araújo, 
2015). Por isso, existem muitas cachoeiras, não somente no Parque, mas também no polo da chapada das Mesas. Segundo o Gestor do PNCM existem 433 nascentes catalogadas pelo IBGE na área do parque e 89 cachoeiras para banho.

Atividades conflitantes estão presentes no PNCM, pois no seu interior há o desenvolvimento da agricultura, pecuária, caça, pesca etc. (IBAMA, 2007). A agricultura de subsistência praticada pelos moradores tradicionais, que utilizam o fogo para a limpeza área para plantação de culturas de subsistência. Os grandes pecuaristas também utilizam o fogo para a limpeza e plantio dos pastos por ser menor o custo. A caça é de subsistência e profissional (IBAMA, 2007).

A situação fundiária também é complexa, de acordo com o gestor do PNCM, existem aproximadamente 130 famílias que estão no interior do parque, $70 \%$ são proprietários, ou seja, tem titularidade de terra. Ainda, não há terras devolutas na área do PNLM. Há uma ocupação consolidada a mais de 100 anos. Portanto, o processo de regularização fundiária se torna muito demorado. Inclusive, a atividade de turismo no PNCM é realizada em terras tituladas, como no caso das Cachoeiras de São Romão e Prata.

Estudos feitos por Jardim (2009) com 65 famílias do entorno e interior do PNCM, e por Silva, Araújo e Conceição (2017) com 40 domicílios no interior do parque, evidenciam as características sociais e econômicas dessas populações. Ambas as pesquisas mostraram que a maioria dos moradores praticam agricultura de subsistência e pecuária (criação de gado). Especificamente, a pesquisa de Jardim (2009) mostrou que as práticas mais comuns na agricultura são: queima $(85,7 \%)$, retirada de árvores $(68,6 \%)$ e roçar $(65,7 \%)$. Portanto, a queima do solo é a prática mais utilizada para a agricultura. Os dados ratificam os levantamentos do IBAMA (2007).

Ambas pesquisas mostraram que a maioria dos moradores são da região do PNLM. Jardim (2009) evidenciou que 52\% têm residido no local a vida toda. Mostrando uma relação de identidade e pertencimento com a área do Parque. Quanto à ocupação da terra, a pesquisa de Jardim (2009) mostrou que 57\% dos moradores são proprietários de terra, dos quais 59\% têm escritura ou certidão de proprietário. Portanto, a maioria tem a titularidade da terra onde mora. Os dados ratificam a informação do gestor do PNCM. Isto se torna um fator complicador no processo de indenização e retirada da população tradicional.

De acordo com o gestor, o PNCM está fechado oficialmente para visitação. Entretanto, o PNCM possui dois atrativos turísticos importantes, que são as Cachoeiras do Prata e de São Romão situadas ao norte do parque. Para visitar essas cachoeiras é necessário contratar o serviço agência de receptivo na cidade de Carolina, cujo transporte com o guia de turismo, é feito por veículos com tração $4 \mathrm{X} 4$ chamados de jardineira.

Na pesquisa de campo constatou-se que, apesar de o turismo ser a principal atividade, não há investimento na infraestrutura do local que é muito precária. Fato também evidenciado por Araújo (2015), ao afirmar que a infraestrutura precisa de melhorias e reparos. Para uma atividade que já acontece há 12 anos, nota-se que há não investimento para atender as necessidades dos visitantes.

Conforme Araújo (2015), não há controle sobre os impactos causados pela visitação e pelos serviços oferecidos, e que o acesso as cachoeiras e outras áreas do parque causam impacto ambiental devido à erosão por causa do solo frágil. 
Nota-se que em ambas as cachoeiras, atividade turística já ocorre há mais 10 anos, porém a infraestrutura é precária.

O ICMBio apontou os principais problemas que ocorrem no PNCM: ocupação irregular/invasão; turismo desordenado; desmatamento no entorno; caça e pesca de subsistência e profissional; uso das APP para atividades de subsistência; espécies exóticas; uso do fogo (Araújo, 2015). Marques (2012) aponta o processo de antropização no PNCM, nas APP para agricultura no topo da chapada, uso de gado extensivo e queimadas para limpeza do pasto e plantio de roças. Os moradores informaram que fazem usam o fogo para fazer suas atividades de subsistência, conforme foi observado na pesquisa de campo no trajeto para as cachoeiras do parque. Eles também mencionaram que não controle e fiscalização e que um dos grandes problemas é lixo causado pelo turismo.

Portanto, todas as atividades de subsistência das comunidades e de turismo fazem o uso e consumo direto dos recursos naturais de uso comum existentes no PNCM, que é incoerente com o objetivo de uma UC de proteção integral. Os problemas/impactos ambientais dificultam a gestão do PNCM. Foi observado na pesquisa de campo, que no PNCM não há controle de visitação porque existem vários acessos para o interior do parque. Muniz (2017) apontou muitos visitantes sem acompanhamento de guia e sem fiscalização no acesso às cachoeiras de são Romão e Prata.

Estudo realizado por Muniz (2017) sobre a capacidade de suporte nas trilhas de acesso as cachoeiras de Prata e São Romão, constatou que as trilhas suportam respectivamente 13 visitas/dia e 28 visitas/dia, estando aquém da realidade de visitas praticadas. Portanto, ambos os casos apontam um número de pessoas acima da capacidade de suporte.

\section{ANÁLISE DOS RESULTADOS SOBRE OS PARNA}

O processo de criação de Áreas Protegidas e/ou Unidades de Conservação foi caracterizado pelas concepções preservacionistas e conservacionistas. De um lado, os que defendiam a criação dessas áreas sem a presença de moradores, os preservacionistas. Do outro lado, os que defendiam a presença de moradores nessas áreas, os conservacionistas. O SNUC foi criado baseado nessas duas concepções, com as UC de proteção integral (uso indireto) e UC de uso sustentável (uso direto). O SNUC estabelece que os PARNA são de proteção integral. Neste sentido, os PARNA dos Lençóis Maranhenses, Jericoacoara e Chapada das Mesas são UC de uso indireto, que não permitem o consumo, a coleta e dano aos recursos naturais.

O PNLM não foi criado no vazio demográfico, pois há centenas de famílias que residem na área desde o século XIX (Terra, 2017). Existem várias localidades e comunidades no PNLM (D`Antona, 2000; Terra, 2017). Notou-se em campo, que as comunidades do PNLM continuam fazendo suas atividades de subsistência baseada na pesca, extrativismo, pecuária, agricultura. Essas atividades foram apontadas pelo estudo de D`Antona (2000) e mencionadas pelo gestor da referida UC.

Todas essas atividades de subsistência são conflitantes devido as restrições e proibições impostas pela legislação do SNUC sobre os PARNA, embora, de acordo com Terra (2017), tenha havido no PNLM restrições ao uso dos recursos naturais 
para a manutenção da subsistência das populações tradicionais. Desse modo, todas as atividades de subsistência praticadas pelas comunidades do PNLM são consideradas ilegais, em oposição ao que estabelece o SNUC. Portanto, nota-se que elas são incompatíveis com a proteção integral (uso indireto).

0 turismo é uma das principais atividades do PNLM iniciada em 2001 (Brasil, 2003). As atividades de turismo afetam diretamente os recursos naturais do PNLM. Contatou-se na travessia de balsa para os Grandes Lençóis que não há nenhuma fiscalização que controle o acesso de visitantes/turistas. 0 gestor reconhece que a fiscalização e o controle de capacidade de carga são fragilidades que dificultam a proteção do PNLM. Também, notou-se que o tráfego de jardineiras causa impacto considerável nas restingas (Áreas de Preservação Permanente) que dão acesso aos grandes lençóis. Esse tipo de veículo é credenciado para condução dos visitantes. Portanto, constata-se o dano ambiental credenciado.

O uso direto se reflete nos impactos ambientais causados pela visitação sem controle, pela ausência de ações de educação ambiental, pelo lixo deixado pelos visitantes e pelo turismo massificado. Silva (2008) constatou o número de visitantes diários excede o limite permitido pelo plano de manejo e que o turismo massificado é que destrói o PNLM, enquanto a comunidade local que pratica atividade de subsistência não pode desenvolver estas atividades por imposição legal. Atualmente, o PNLM convive com um paradoxo que vai de encontro ao que estabelece o SNUC sobre os PARNA, pois quem causa danos tem direito a usufruir, mas quem vive lá e o preserva tem que ser retirado.

Quanto à Jericoacoara, era uma comunidade de pescadores, que começou a sofrer especulação imobiliárias. Mas, para essa especulação e preservar o território, a APA Jericoacoara foi criada, porém não teve o efeito esperado, pois os danos causados pela especulação imobiliária não cessaram (Brasil, 2011). Por isso, o PNJ foi criado, uma categoria de UC mais restritiva. Entretanto, mesmo com a proteção integral, o uso dos recursos naturais continua acontecendo.

As comunidades do PNJ ainda mantêm suas atividades de subsistência com base agricultura, pecuária e recursos pesqueiros. As atividades de subsistência representam não somente o uso direto, mas também impactos sobre os recursos naturais do PNJ, que serão mitigados com o reassentamento das famílias, conforme prevê o SNUC. A Vila de Jericoacoara situada na ZA do parque, também exerce impacto direto, conforme apontou Brasil (2011).

Os problemas ambientais apontados anteriormente pelos moradores locais e pelo gestor da PNJ, durante a pesquisa de campo parecem que não cessaram. Um exemplo é o excesso de turistas constatado na Duna Pôr-do-Sol, que está causando sua diminuição, conforme relatado pelo gestor e evidenciado pelo estudo Meireles, Gorayeb e Pereira Filho (2018). Ressalta-se que as áreas de dunas são APP. Portanto, o estudo evidenciou que a proteção integral não existe, porque tanto os moradores locais, quanto as atividades turísticas fazem uso direto dos recursos naturais de uso comum do PNJ.

Em relação ao PNCM, foi criado para preservar a natureza, principalmente as cachoeiras, que seriam impactadas com a construção de pequenas hidrelétricas no rio Farinha. Se a intenção de criar o PNCM era a proteção integral, parece que ainda não teve o resultado esperado, mesmo após 16 anos de sua criação. Entre os principais entraves estão as atividades de subsistência, a indenização dos proprietários e posseiros que ainda moram no interior no PNCM. 
A consequência, é que a proteção integral simplesmente não acontece no PNCM, conforme os problemas e a antropização mencionadas anteriormente, especialmente sobre atividades de turismo nas propriedades privadas onde estão localizadas cachoeiras do Prata e São Romão. Nelas, a infraestrutura criada pelos proprietários foi feita sem critérios técnicos, somente para acomodação dos visitantes (Muniz, 2017). Também não existe controle de acesso sobre o número de visitantes e a fiscalização é precária, apesar de o PNCM está oficialmente fechado.

Notou-se, também o excesso de visitantes na cachoeira do Prata incompatíveis com a proteção integral pretendida. O estudo de Muniz (2017) sobre capacidade de suporte aponta 13 visitas/dia. Portanto, a visitação excede o limite da capacidade de suporte calculado, causando um impacto por excesso de visitante na trilha. Situação semelhante constatou-se na cacheira de São Romão pelo excesso de visitantes, o que vai de encontro ao estudo de Muniz (2017), que é 28 visitas / dia. Assim, deveria ser limitado o número de visitantes nas cachoeiras.

Desse modo, verifica-se que o conceito de uso direto da IUCN se aplica aos três PARNAS, constatado pelas atividades de subsistência e turismo. Quanto à exclusão e subtração dos recursos de uso comum (Ostrom at al., 1994), constata-se a difícil exclusão dos beneficiários (turistas e o trade turístico) e alta subtração dos pelos turistas e moradores locais.

\section{CONSIDERAÇÕES FINAIS}

Este estudo apontou que não há uso indireto nos PNLM, PNJ e PNCM. Desse modo, prevalece o uso direto dos recursos naturais de uso comum, conforme o conceito da IUCN, visto que tais recursos são usados e consumidos pelos moradores locais e pelas atividades turísticas. Também chama atenção para um problema que é negligenciado na criação de UC de proteção integral.

Sabe-se que nos PARNA que a retirada dos moradores é mandatória, por meio da desapropriação. Isto gera conflito de várias ordens tais como: perda da identidade ao território, valor das indenizações, limitações às atividades de subsistência etc. Desse modo, precisa-se refletir sobre a real necessidade da retirada das populações dos PARNA. Isto também poderia ser revisto, por exemplo, com a criação de zonas de permanência dessas populações. Deve-se estimular os debates sobre a permanência das comunidades, pois elas podem contribuir para a conservação desta categoria de UC.

0 turismo, também, precisa ser revisto e repensado nos PARNA. Apesar de ser considerada uma atividade de uso indireto, este estudo demonstrou o uso massificado, sem controle de acesso e sem limitação de turistas/visitantes nos três PARNA. A dificuldade de excluir os visitantes e alta subtração de recursos de uso comum é o desafio do turismo nos PARNA. Somente um controle efetivo associado a um estudo de capacidade de suporte dos visitantes nos PARNA, poderá reverter a situação. Espera-se que este estudo contribua para pesquisas e debates o uso indireto nos PARNAS. 


\section{REFERÊNCIAS}

Araújo, M. N. F. (2015). Governança ambiental e turismo - análise dos Parque Nacionais: Amazônia, Chapada das Mesas (Brasil) e Tortuguero (Costa Rica). 375 f. (Tese de Doutorado). Universidade Federal do Pará, Programa de Pós-Graduação em Desenvolvimento Sustentável do Trópico Úmido, Belém, PA, Brasil.

Augé, M. (1994). Não-lugares: introdução a uma antropologia da supermodernidade. São Paulo: Papirus.

Babbie, E. (1999). Métodos de pesquisa de survey. Belo Horizonte: UFMG.

Barreto Filho, H. T. (2010). Uma perspectiva antropológica sobre a unidades de conservação de proteção integral na Amazônia brasileira. In: Almeida, A. W. B.; Farias Junior, E. de A. (Org.). Mobilizações Étnicas e Transformações Sociais no Rio Negro. Manaus: UEA Edições. p. 147-210.

Bernard, H. R. (1995). Research methods in anthropology: qualitative and quantitative approaches. 2. ed. WalnutCreek: Altamira Press. 584 p.

Brasil. (1934). Decreto n. 23.793, de 23 de janeiro, aprova o código florestal. Referenciado de: http://www2.camara.leg.br/legin/fed/decret/1930-1939/decreto-23793-23janeiro-1934-498279-norma-pe.html

Brasil. (1965). Lei n. 4.771, de 15 de setembro, que institui o novo código florestal. Referenciado de: http://www2.camara.leg.br/legin/fed/lei/1960-1969/lei-477115-setembro-1965-369026-publicacaooriginal-1-pl.html

Brasil. (1979). Plano do Sistema de Unidades de Conservação do Brasil. Instituto Brasileiro de Desenvolvimento Florestal. Brasília: IBDF.

Brasil. (1984). Decreto n. 90.379, de 29 de outubro, dispõe sobre a implementação de Área de Proteção Ambiental no Município de Acaraú, no Estado do Ceará, e dá outras providências. Referenciado de: http://www.planalto.gov.br/ccivil_03/decreto/antigos/ d90379.htm

Brasil. (2002). Decreto $s / n$. de 4 de fevereiro, cria o Parque Nacional de Jericoacoara, redefine os limites da Área de Proteção Ambiental de Jericoacoara, no Estado do Ceará, e dá outras providências. Referenciado de: http://www.planalto.gov.br/ccivil_03/ Dnn/2002/Dnn9492.htm

Brasil. (2003). Plano de Manejo do Parque Nacional dos Lençóis Maranhenses. Instituto Brasileiro do Meio Ambiente e Recursos Naturais Renováveis. São Luís.

Brasil. (2003). Plano de Manejo do Parque Nacional dos Lençóis Maranhenses. IBAMA.

Brasil. (2005). Decreto de 12 de dezembro de 2005. Cria o Parque Nacional de Chapada das Mesas, nos municípios de Carolina, Riachão e Estreito, no estado do Maranhão. D.O.U de 13/12/2005. Recuperado em 04 de agosto de 2018 de http://www.planalto.gov. br/ccivil_03/_ato2004-2006/2005/dnn/dnn10718.htm

Brasil. (2008). Unidades de Conservação da Natureza. (Coleção Ambiental; v. 8). Brasília: Senado Federal, Subsecretaria de Edições Técnicas.

Brasil. (2011). Plano de Manejo do Parque Nacional de Jericoacoara. Brasília: ICMBio.

Camargo, A. A. (1978). 0 ator, o pesquisador e a história: impasses metodológicos na implantação do centro de pesquisa e documentação de história contemporânea do Brasil. In: Nunes, E. O. (Org.). A aventura sociológica: objetividade, paixão, improviso e método na pesquisa social. Rio de Janeiro: Zahar. p. 276-304.

Colchester, M. (2003). Salvaging nature: indigenous peoples, protected areas and biodiversity conservation. World Rainforest Moviment. Montevideo. Recuperado a partir de https:// www.researchgate.net/publication/284691747 
D’Antona, A. O. (2002). O verão, o inverno e o inverso: Lençóis Maranhenses, imagens. Brasília: IBAMA.

Diegues, A. C. (2001). O Mito moderno da natureza intocada. São Paulo: HUCITEC.

Ecoturismo, São Paulo, v.12, n. 2, mai/jul, pp.170-188. Referenciado de: http://www. periodico.unifesp.br/index.php/ecoturismo/issue/view/413.

Fenny, D., Berkers, F., McCay, B. J., \& Acheson, J. M. (1990). The tragedy of the commons: twenty-two years later. Human Ecology, v.18, n.1, pp.1-19. http://www.jstor.org/ stable/4602950.

Fonteles, J. O. (2005). Reconstrução de território e identidade: um olhar sobre Jericoacoara - Ceará. Mercator - Revista do Departamento de Geografia UFC, v. 4, n.8. jul-dez, pp. 47-54. http://www.mercator.ufc.br/mercator/article/view/98

Hardin, G. (1968). The tragedy of the commons. Science, v. 162, pp. 1241-1248. http:// www.science.sciencemag.org/content/162/3859/1243.

[IBAMA] Instituto Brasileiro de Meio Ambiente e dos Recursos Naturais Renováveis. (2007). Plano operativo de prevenção e combate aos incêndios florestais do Parque Nacional da Chapada das Mesas.

[IUCN] International Union for Conservation of Nature. (1998). Economic values of protected areas: guidelines for protected areas managers. The World Conservation Union: Gland, Switzerland and Cambridge, UK.

Jardim, E. L. (2009). Parque Nacional da Chapada das Mesas: caracterização socioeconômica da população. IV Jornada Internacional de Políticas Públicas.

Loreau, M. (2014). Reconciling utilitarian and non-utilitarian approaches to biodiversity conservation. Ethics Sci Environ Polit, v.14, pp. 27-32. http://www.int-res.com/ articles/esep2014/14/e014p027/pdf.

Machado, R. V. (2013). Ecoturismo, contornos, principais problemas e a análise da atividade do Parque Nacional de Jericoacoara. 163 f. (Dissertação de Mestrado). Universidade de Coimbra, Programa de Pós-Graduação em Ciências Jurídico-políticas, Coimbra.

Marconi, M. A., \& Lakatos, E. M. (2003). Fundamentos de metodologia científica. São Paulo: Atlas.

Marques, A. R. (2012). Saberes geográficos integrados aos estudos territoriais sob a ótica da implantação do Parque Nacional da Chapada das Mesas, Sertão de Carolina/MA. 201 f. (Tese de Doutorado). Universidade Estadual Paulista, Programa de Pós-Graduação em Geografia, São Paulo.

Medeiros, R. (2006). Evolução das tipologias e categorias de áreas protegidas no Brasil. Revista Ambiente \& Sociedade, v. IX, n. 1, jan/jun. pp. 41-64. http://www.scielo.br/j/ asoc/aC4CWbLfTKrTPGzcN68d6N5v/!format=pdf\&lang=pt

Meireles, A. J., Gorayeb, A., \& Pereira Filho, N. S. (2018). Campos de dunas em Jericoacoara: intervenções humanas como possível indicador de mudança na dinâmica morfológica. Confins - Revista franco-brasileira de geografia, n. 34, pp.1-17. http://www.jornauls. openedition.org/confins/12872

Molina, F. S. (2007). Turismo e produção do espaço: o caso de Jericoacoara, CE. $150 \mathrm{f}$. (Dissertação de Mestrado). Universidade de São Paulo, Pós-Graduação em Geografia Humana, São Paulo.

Moreira, H., \& Caleffe, L. G. (2008). Metodologia da pesquisa para o professor pesquisador. $2^{\text {a }}$ Ed. Rio de Janeiro: Lamparina.

Muniz, G. P. S. (2017). Ecoturismo em Carolina-Maranhão: que prática é essa? 205 f., (Dissertação de Mestrado). Universidade Estadual do Maranhão, Programa de PósGraduação em Geografia, natureza e dinâmica do espaço, São Luis, Brasil. 
Nash, R. F. (1967). Wilderness and the American mind. Yale University.

Oliveira, M. M. (2007). Como fazer pesquisa qualitativa. Petrópolis, Vozes.

Oliveira, S. L. (1998). Tratado de metodologia científica: projetos de pesquisas, TGI, TCC, monografias, dissertações e teses. São Paulo: Pioneira, 320 p.

Ostrom, E. (1998). A behavioral approach to the rational choice theory of collective action. American Political Science Review, v. 92, n.1, march, pp. 1-22. D0I: https:// doi.org/10.2307/2585925

Ostrom, E. (1999). Coping with the tragedies of the Commons. Annu. Rev. Polit. Sci. v. 2, pp. 493-535. http://www.annualreviews.org/doi/abs/10.1146/annurev.polisci.2.1.493.

Ostrom, E. (2002). Reformulating the commons. Ambiente \& Sociedade, Ano V, n. 10, pp. 1-21. http://www.scielo.br/j/asoc/a/b9vdr8nFV3FNpnwtZNK86CC/?lang=en\&format=pdf.

Ostrom, E., Gardner, R., \& Walker, J. (1994). Rules, games and common-pool resources. The University of Michigan Press.

Pinto, P. M., \& Souza, J. A. A. (2020). Mapas de localização dos Parques Nacionais dos Lençóis Maranhenses, Jericoacoara e Chapada das Mesas. Sistemas de Coordenadas Geográficas SIRGAS 2000 UTM 22S, Base cartográfica BCIM-IBGE, 2018, Belém, PA: LAIG/UFPA.

Santana, V. F., Fontes Filho, J. R., \& Rocha, S. B. (2015). Gestión local de recursos de uso común en turismo: la perspectiva de Elinor Ostrom. Estudiosy Perspectivas en Turismo, v. 24, pp. 56-75. http://www.estudiosenturismo.com.ar/pdf/V24/N01/v24n1a04.pdf.

Schlüter, R. G. (2003). Metodologia da pesquisa em turismo e hotelaria. $2^{2}$ Ed. São Paulo: Aleph.

Semeia. (2015). Diagnóstico do uso público em parques nacionais brasileiros: a perspectiva dos gestores. Recuperado em 17 de agosto de 2018 de http://semeia.org.br/publicacoes.php.

Severino, A. J. (2007). Metodologia do trabalho científico. São Paulo: Cortez.

Silva, D. B. (2008). Turismo em Unidades de Conservação: contribuições para uma prática de uma atividade turística sustentável no Parque Nacional dos Lençóis Maranhense. 207 f. (Dissertação de Mestrado). Universidade de Brasília, Programa de Pós-Graduação em Desenvolvimento Sustentável, Brasília, DF, Brasil.

Silva, M. L. A., Araújo, M. F. V., \& Conceição, G. M. (2019). Síntese histórica e socioambiental do Parque Nacional da Chapada das Mesas (MA). Revista Brasileira de

Silva, M. L. A., Araújo, M. F. V., \& Conceição, G. M. (2017). Identidade e modo de vida dos moradores do Parque Nacional da Chapada das Mesas, Maranhão, Brasil. Biota Amazônia, Macapá, v.7, n.4, pp.41-47. DOI: http://dx.doi.org/10.18561/2179-5746/ biotaamazonia.v7n4p41-47

Simonetti, S. R., \& Nascimento, E. P. (2012). Uso público em unidades de conservação: fragilidades e oportunidades para o turismo na utilização dos serviços ecossistêmicos. Somanlu, 12, n.1, jan-jun, pp.173-190. http://www.periodicos.ufam.edu.br/index. php/somanlu/article/view/465.

Terra, A. (2017). Conflitos socioambientais na gestão do Parque Nacional dos Lençóis Maranhenses: o caso das comunidades Tratada de Cima, Tratada de Baixo e Buritizal. Bol. Goia. Geogr. (online). Goiânia, v.37, n.2, maio/ago. pp.245-263. http://www. revistas.ufg.br/bgg/article/view/49154.

Vallejo, L. R. (2013). Uso público em áreas protegidas: atores, impactos, diretrizes de planejamento e gestão. Anais - Uso Público em Unidades de Conservação, n. 1, v. 1. http://www.periodicos.uff.br/uso_publico/article/view/28674. 


\section{CONTRIBUIÇÕES}

Raul Ivan Raiol de Campos: Definição do problema de pesquisa e objetivos, desenvolvimento da proposição teórica, realização da revisão bibliográfica e fundamentação teórica, escolha dos procedimentos metodológicos, coleta e análise de dados, revisão crítica, redação e adequação do manuscrito às normas da RTA.

Paulo Moreira Pinto: Definição do problema de pesquisa e objetivos, desenvolvimento da proposição teórica, realização da revisão bibliográfica e fundamentação teórica, escolha dos procedimentos metodológicos, elaboração de tabelas, gráficos e figuras, revisão crítica, redação e adequação do manuscrito às normas da RTA.

Silvia Helena Ribeiro Cruz: Desenvolvimento da proposição teórica, realização da revisão bibliográfica e fundamentação teórica, escolha dos procedimentos metodológicos, coleta e análise de dados.

Fabrício Lemos de Siqueira Mendes: Realização da revisão bibliográfica e fundamentação teórica, escolha dos procedimentos metodológicos, coleta e análise de dados. 